Federal Reserve Bank of Minneapolis

Research Department Staff Report 494

Revised March 2014

\title{
A Reassessment of Real Business Cycle Theory*
}

Ellen R. McGrattan

University of Minnesota

and Federal Reserve Bank of Minneapolis

Edward C. Prescott

Arizona State University

and Federal Reserve Bank of Minneapolis

\begin{abstract}
During the downturn of 2008-2009, output and hours fell significantly while labor productivity rose. These facts have led many to conclude that there is a significant deviation between observations and current macrotheories that assume business cycles are driven, at least in part, by fluctuations in total factor productivities of firms. We show that once investment in intangible capital is included in the analysis, there is no inconsistency. Measured labor productivity rises if the fall in output is underestimated; this occurs when there are large unmeasured intangible investments. Microevidence suggests that these investments are large and cyclically important.
\end{abstract}

Keywords: intangible capital, business cycles, productivity JEL classification: E13, E32

*McGrattan: erm@umn.edu; Prescott: edward.prescott@asu.edu. We thank Dirk Krueger for helpful comments. The views expressed herein are those of the authors and not necessarily those of the Federal Reserve Bank of Minneapolis or the Federal Reserve System. 
During the downturn of 2008-2009, output and hours fell significantly while labor productivity rose. These observations have led many economists to conclude that this recession was not typical and certainly not consistent with the predictions of current macrotheories that assume business cycles are driven, at least in part, by fluctuations in total factor productivities of firms. With credit spreads rising and asset prices plummeting, many looked to what seemed like an obvious alternative explanation, namely, that disruptions in financial markets were the source of declines in real activity.

While this alternative theory sounds plausible, we question the original premise that the 2008-2009 episode is inherently different. We are motivated by the fact that this recession has many of the same features of the 1990s technology boom, only in reverse. (See McGrattan and Prescott 2010, 2012.) To this end, we show that one small modification of the business cycle models dating back to those developed by Kydland and Prescott (1982) and Long and Plosser (1983) yields predictions that are consistent with the facts. (The same can be said for later variants of these models that introduced monetary and fiscal factors, monopolistic competition, nominal and real rigidities, heterogeneity of households and firms, and so on.)

The modification we make is to include both tangible and intangible investments in a business cycle model that combines many of the features previously introduced. We assume that firms produce goods and services for final and intermediate uses and that they also produce new intangible capital goods such as research and development (R\&D), software, brand equity, and organizational capital. Intangible capital can be used nonrivalrously as an input to both activities.

In 2008, only a small part of all intangible investment was included in the measure of GDP from the Bureau of Economic Analysis (BEA). As a result, the fact that labor 
productivity rose between 2008 and 2009 is not inconsistent with theoretical predictions. The intuition is simple: during a downturn, measured labor productivity rises if we significantly underestimate the drop in total output. We underestimate the drop in total output if there are large unmeasured investments.

In this short paper, we describe the basic theory and an extension incorporating intangible investments. We then review some of the microevidence showing that intangible investments are not only large - especially for high-technology sectors that have important input-output linkages with other sectors-but also highly correlated with tangible investments like equipment.

We conclude by describing a future research project that delves deeper into the question of whether there are in fact significant deviations between theory and observation.

\section{The Basic Theory}

The basic theory has a stand-in household that supplies labor to competitive firms and receives dividends as owners of these firms. There is a government with certain spending obligations that are financed by various taxes on households and firms. Firms produce final goods for households and the government and intermediate inputs for other firms. The sources of fluctuations in the economy are stochastic shocks to firm productivities, to government spending needs, and to tax rates. (A version of this model without government spending or taxes is quantitatively analyzed in Horvath 2000.) Here, we describe the environment and review the model's main predictions in light of recent events.

There are $S$ production units, or "sectors," that produce final goods for households and the government and intermediate inputs for other sectors. The production function for a 
firm in sector $s$ is $y_{s t}=a_{s t} k_{s t}^{\theta_{s}} h_{s t}^{\nu_{s}} m_{s t}^{\gamma_{s}}$, with $1=\theta_{s}+\nu_{s}+\gamma_{s}$, where $y$ is gross output, $a$ is a stochastic parameter governing the state of technology, $k$ is the capital input, $h$ is the labor input, and $m$ is a composite of intermediate inputs, that is, $m_{s t}=\prod_{l=1}^{S} m_{l s t}^{\gamma_{l s} / \gamma_{s}}$. Variables are in per capita terms and population grows at the rate $g_{n}$.

Firms in sector $s$ maximize the present discounted stream of dividends, $\left\{d_{s t}\right\}$, paid to their shareholders, which are the households:

$$
\max E_{0} \sum_{t=0}^{\infty} \beta^{t} \frac{\partial u\left(c_{t}, \ell_{t}\right)}{\partial c_{t}} \frac{\left(1-\tau_{d t}\right) d_{s t}}{p_{t}}
$$

where $\tau_{d}$ is the tax rate on households' dividends and $p$ is the aggregate price level. The discount factor is the marginal utility of household consumption, where utility $u$ is defined over consumption $c$ and leisure $\ell$. Dividends are earnings $p_{s} y_{s}$ less payments to labor $w_{s} h_{s}$, purchases of intermediate goods $p_{s}^{m} m_{s}$, new investments $x_{s}$, and corporate property and income taxes:

$$
\begin{aligned}
d_{s t}=p_{s t} y_{s t}-w_{s t} h_{s t}-p_{s t}^{m} m_{s t}-p_{s t} x_{s t}-\tau_{k t} p_{s t} k_{s t} \\
-\tau_{p t}\left\{p_{s t} y_{s t}-w_{s t} h_{s t}-\left(\delta_{s}+\tau_{k t}\right) p_{s t} k_{s t}-p_{s t}^{m} m_{s t}\right\}
\end{aligned}
$$

where $\tau_{k}$ and $\tau_{p}$ are the property and income tax rates, respectively, and $\delta_{s}$ is the rate of depreciation of capital in sector $s$. Assuming, again, that variables are in per capita units, next period capital is given by $k_{s t+1}=\left[\left(1-\delta_{s}\right) k_{s t}+x_{s t}\right] /\left(1+g_{n}\right)$.

Labor is supplied by households that are also firm shareholders. Household members jointly maximize expected utility: $E_{t} \sum_{t=0}^{\infty} \beta^{t} u\left(c_{t}, \ell_{t}\right) N_{t}$, where $c_{t}=\left[\int \omega_{s} c_{s t}^{(\rho-1) / \rho} d s\right]^{\rho /(\rho-1)}$ is the per capita consumption index that aggregates sectoral consumptions $\left\{c_{s t}\right\}, \ell_{t}=1-\sum_{s} h_{s t}$ is the per capita leisure index, $h_{s t}$ is the labor supplied to sector $s$, and $N_{t}=\left(1+g_{n}\right)^{t}$ is the 
number of household members. The household budget each period is given by

$$
\left(1+\tau_{c t}\right) \sum_{s} p_{s t} c_{s t}+\sum_{s} v_{s t} s_{s t+1} \leq\left(1-\tau_{h t}\right) \sum_{s} w_{s t} h_{s t}+\sum_{s}\left(v_{s t}+\left(1-\tau_{d t}\right) d_{s t}\right) s_{s t},
$$

where $\tau_{c}$ and $\tau_{h}$ are taxes on consumption and labor, respectively, and $v_{s t}$ is the price of an additional share in sector $s$ firms, with $s_{s t}$ owned at time $t$. If the aggregate supply of shares is one, then $v_{s t}$ is also the total value of sector $s$ firms.

The resource constraint in this economy, which closes the model, is given by

$$
c_{s t}+x_{s t}+\sum_{l=1}^{S} m_{s l t}+g_{s t}=y_{s t}
$$

where $g_{s t}$ is purchases of goods and services by the government. Once stochastic processes for the exogenous variables - $a_{s t}, g_{s t}, \tau_{c t}, \tau_{d t}, \tau_{h t}, \tau_{p t}, \tau_{k t}$-have been specified, it is straightforward to compute a log-linear approximation to the competitive equilibrium of this economy.

\section{A. Naive Critique}

A naive critique of the theory just described is that it lacks disruptions in financial markets and is, therefore, not relevant for studying episodes such as the 2008-2009 downturn. While it is true that we have not incorporated the vast number of financial instruments and markets that do in fact exist, it is a non sequitur to argue that the theory is therefore not relevant for analyzing investment, employment, or output. At issue is whether the theory is a good abstraction for making reliable predictions when studying business cycles or analyzing changes in policy. Since a large part of business investment is made by large corporations that are able to easily raise funds with retained earnings, equity, or bond issues, it may well be a fine approximation to assume that all firms are able to do so. If they were not able to do so, but had good projects, the larger firms would simply acquire them. 


\section{B. Sophisticated Critique}

A more sophisticated critique of the basic theory involves assessing whether there are significant deviations between the model predictions and observations on output, investment, and employment.

To be concrete, let's consider the simplest version of the model with no input-output linkages (that is, with $S=1$ ) and no fluctuations in taxes or government spending. In this version, oftentimes referred to as the one-sector growth model, aggregate fluctuations are driven by the Solow residual $a_{t}$ of the aggregate production technology. We can construct the empirical analogue of the Solow residual using national account data from the BEA for output and capital and household survey data from the Bureau of Labor Statistics (BLS) for the total labor input. Doing so, we find several periods when there were large movements in output or employment without much change in the Solow residual. For example, during the technology boom of the 1990s, the Solow residual was near its trend for most of the decade, and during the recession of 2008-2009, the Solow residual fell only slightly below trend. Feeding the Solow residual into the model would not have enabled us to predict the 1990s technology boom or the downturn of 2008-2009.

One can further diagnose the source of these deviations between theory and data by applying the business cycle accounting method of Chari, Kehoe, and McGrattan (2007). Doing so in McGrattan and Prescott $(2010,2012)$, we find the theory requires time-varying labor wedges, that is, something affecting $\tau_{h t}$ in addition to government tax policy. Adding back the input-output linkages cannot help along this dimension if labor is perfectly substitutable across sectors, because labor productivities of all sectors, namely, $p_{s t} y_{s t} / h_{s t}$, are equated and 
thus equal to the aggregate labor productivity, and there are no additional sources of time variation in the labor wedge.

\section{An Extension with Intangible Capital}

If we modify the basic theory to incorporate intangible capital, we find that the model produces the needed time-varying labor wedge. We use this fact to demonstrate that measured productivities are misleading statistics for judging the theory.

The main extension is in the description of the technology. We now assume that there are two types of capital inputs: tangible capital and intangible capital. Tangible capital includes structures and equipment, both of which are capitalized. Intangible capital includes research and development, software, artistic originals, brand equity, and organizational capital, all of which are expensed when computing taxable income.

In addition to different tax treatment, tangible and intangible capital differ in how they can be used. We assume that intangible capital, $k_{I}$, can be used simultaneously in producing new intangible capital and in producing goods and services for final use and intermediate inputs, while tangible capital, $k_{T}$, cannot. More specifically, we assume that the technologies of the firms in sector $s$ are

$$
\begin{aligned}
y_{s t} & =a_{s t}\left(k_{T, s t}^{1}\right)^{\theta_{s}}\left(k_{I, s t}\right)^{\phi_{s}}\left(h_{s t}^{1}\right)^{\nu_{s}}\left(m_{s t}^{1}\right)^{\gamma_{s}} \\
x_{I, s t} & =b_{s t}\left(k_{T, s t}^{2}\right)^{\theta_{s}}\left(k_{I, s t}\right)^{\phi_{s}}\left(h_{s t}^{2}\right)^{\nu_{s}}\left(m_{s t}^{2}\right)^{\gamma_{s}},
\end{aligned}
$$

with $\theta_{s}+\phi_{s}+\nu_{s}+\gamma_{s}=1$, where the first activity (with inputs superscripted with a 1) produces new output that can be used for consumption, tangible investment, and new intermediate goods and the second activity (with inputs superscripted with a 2) produces new intangible 
investment. Notice that $k_{I, s t}$ does not have a superscript.

The maximization problem for firms in sector $s$ remains the same: maximize the expected stream of after-tax dividends in equation (1). However, the definition of dividends is now different. We replace all appearances of $k_{s t}$ and $x_{s t}$ in (2) with $k_{T, s t}$ and $x_{T, s t}$, respectively. We also add a constraint for next period intangible capital, namely, $k_{I, s t+1}=\left[\left(1-\delta_{I s}\right) k_{I, s t}+x_{I, s t}\right] /\left(1+g_{n}\right)$. As before, the household earns income from dividends and wages and maximizes expected utility subject to the sequence of budget constraints in equation (3).

Next, we show that these minor adaptations of the basic theory can have a significant effect on the key predictions. Prior to the BEA's 2013 comprehensive revision of the national accounts, nearly all intangible investments were not included in measures of business value added and, therefore, GDP. (Only software investments were included at that time.) In a typical downturn, GDP falls but investments fall by more in percentage terms. By measuring labor productivity as the ratio of GDP to the total labor input, one underestimates the fall in total output that includes the unmeasured investment. In other words, true labor productivity is proportional to $\left(p_{s t} y_{s t}+q_{s t} x_{I s t}\right) / h_{s t}$, not to typical measures of productivity such as $p_{s t} y_{s t} / h_{s t}$ or something in between (assuming only a fraction of intangible investments can be adequately measured). Notice that here, unlike in the basic model, we get a nontrivial labor wedge because $q_{s t} x_{I s t} / h_{s t}$ is time varying, and, as we have shown in earlier analyses of the aggregate data, it fluctuates in just the right way.

Thus, there is no logical inconsistency between theory and aggregate data. The question then is whether the theory is consistent with microdata. 


\section{Microevidence}

We turn next to microevidence on tangible and intangible investments. The evidence shows that intangible investments for which we have direct measures are large and correlated with tangible investments, especially equipment. We also find that intangible-intensive industries produce a lot of intermediate inputs, implying that they can indirectly affect less intangibleintensive industries, further complicating analyses of sectoral productivities.

In 2013, the BEA expanded its coverage of intangibles beyond software to include investment in research and development and artistic originals and created a new category of fixed investment called intellectual property products. To give some sense of the size of this category, consider adding up all private fixed nonresidential investment and splitting it into the three categories: structures, equipment, and intellectual property. In 2012, we find that 22 percent of the investment is in structures, 45 percent in equipment, and 33 percent in intellectual property. And, if we look across time, these percentages have been roughly constant since the start of the technology boom in the early 1990s.

In some industries, the ratios are even more striking. Consider, for example, the investment data shown in Figure 1 for two intangible-intensive industries: computer and electronic products and information. For each, we divided the investment series by a trend, which is computed by multiplying the GDP deflator, population, and a growth factor of $1.019^{t}$ to account for technological growth. We then divided each series for a particular industry by the total private fixed investment in 2007, so that the components add to 100 in that year.

These data have several noteworthy features. First, we see that investments in intellectual property for these industries are large. In the case of computer products, intellectual 
property investments are currently about four times larger than investment in both equipment and structures. Information, like other information and communications technology industries (ICT), has grown dramatically since the 1970s and has become more R\&D intensive over time. Interestingly, over time, we have seen a decline in this industry's equipment investment and an offsetting increase in intellectual property products. A second noteworthy feature of these data is the correlation between the investment series, especially between intellectual property and equipment. Spending on software and R\&D grew rapidly in the 1990s during the technology boom. This peaked in 2000 and has subsequently fallen, then risen, then fallen again in the 2008-2009 downturn. The series for equipment is very similar.

Even more remarkable about these data is the fact that the BEA does not include the many other intangible investments such as advertising, marketing, and organizational capital because it does not have adequate measures of these expenditures. If the BEA did include these investments, Figure 1 would look even more dramatic.

Other sources of data give us some information about fluctuations in intangible investments over time. For example, in the case of advertising expenditures, which is at least as large as R\&D spending in the aggregate, we have company expenses reported on annual 10-K reports for the Securities and Exchange Commission (and available through COMPUSTAT). In Table 1, we report statistics for the top 500 domestic companies that have to file 10-Ks, sorting first on total advertising expenses and then on total R\&D expenses in 2008. In 2008, the top 500 advertisers and the top 500 R\&D spenders did close to all the spending on advertising and R\&D, respectively, and had significant tangible capital expenditures, sales, and employment. During the subsequent year, both groups faced large declines in all categories of investments, including capital expenditures for property, plant, and equipment. 
Furthermore, a plot of the time series (not shown) shows that the changes in the investment series are highly correlated.

Finally, we want to point out that there are important input-output linkages between companies that make significant intangible investments and others that do not. According to the BEA's 2007 input-output tables, 66 percent of output from manufacturing, information, and professional and business services has intermediate uses, and much of that output is in sectors that do less intangible capital investment.

In summary, intangible investments are large, and the evidence shows that they are correlated with tangible investments and potentially have an impact on a large number of sectors through input-output linkages. This is important because it means that standard measures of the Solow residuals are not reliable indicators of actual fluctuations in productivity.

\section{Future Research}

To be useful, economists need reliable theory for policy analysis, and any serious challenges to existing theory must demonstrate that there are important deviations between theoretical predictions and observations - deviations that imply we'll get the wrong answer to key policy questions. The microevidence suggests that our basic macrotheory - extended to incorporate intangible investments - is worthy of further investigation before declaring it useless. What is needed now is a full quantitative analysis of the extended model of Section II that relies on both macroevidence from the national accounts and microevidence from firm-level and industry data. We need parameter estimates and a working laboratory to test our hypotheses. The main challenge we face is to use our theory in innovative ways to measure what cannot be directly measured. 


\section{References}

Chari, V.V., Patrick J. Kehoe, and Ellen R. McGrattan. 2007. "Business Cycle Accounting." Econometrica 75 (3): 781-836.

Horvath, Michael. 2000. "Sectoral Shocks and Aggregate Fluctuations." Journal of Monetary Economics 45 (1): 69-106.

Kydland, Finn E., and Edward C. Prescott. 1982. "Time to Build and Aggregate Fluctuations." Econometrica 50 (6): 1345-70.

Long, John B., Jr., and Charles I. Plosser. 1983. "Real Business Cycles." Journal of Political Economy 91 (1): 39-69.

McGrattan, Ellen R., and Edward C. Prescott. 2010. "Unmeasured Investment and the Puzzling U.S. Boom in the 1990s." American Economic Journal: Macroeconomics $2(4): 88-123$.

McGrattan, Ellen R., and Edward C. Prescott. 2012. "The Labor Productivity Puzzle." In Government Policies and the Delayed Economic Recovery, edited by Lee E. Ohanian, John B. Taylor, and Ian J. Wright, 115-54. Stanford, CA: Hoover Institution Press. 

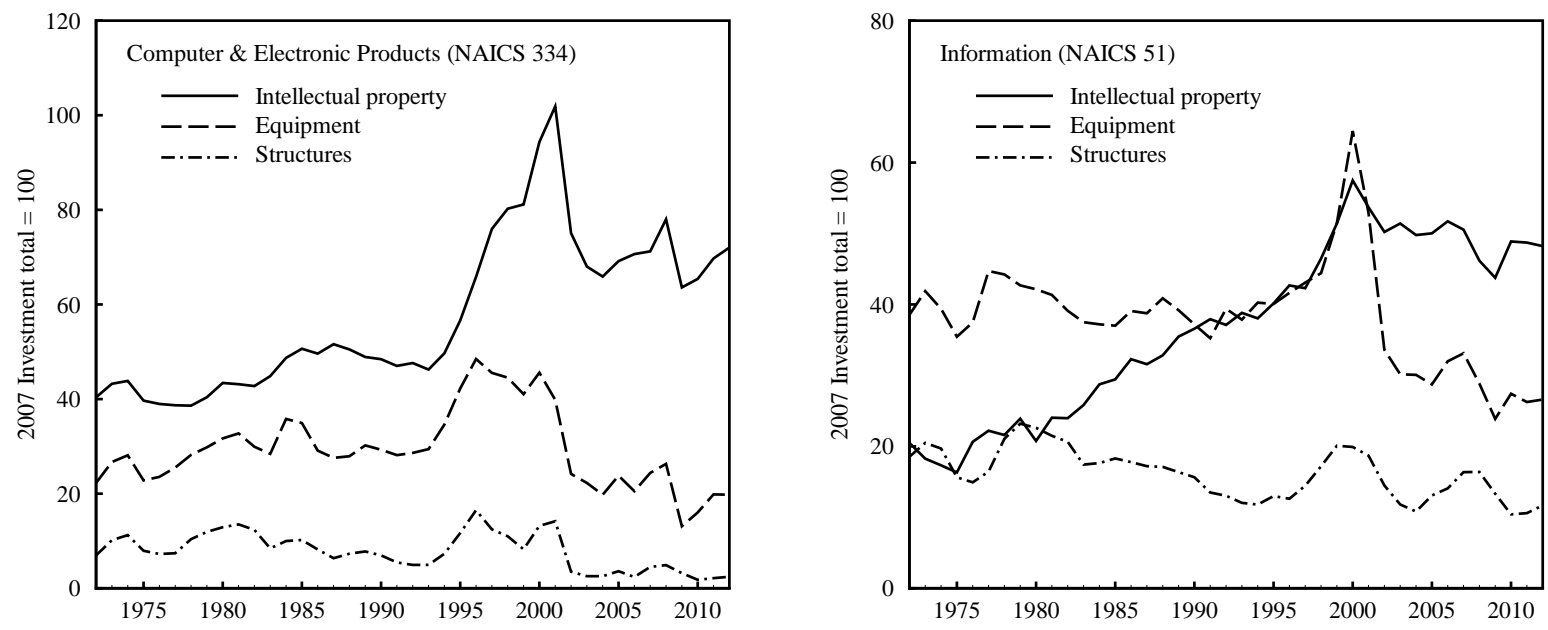

Figure 1. Private Fixed Investments in Two Industries (Source: BEA)

\begin{tabular}{lccccc}
\hline & \multicolumn{2}{c}{ Top 500 Advertisers } & & \multicolumn{2}{c}{ Top 500 R\&D Spenders } \\
\cline { 2 - 3 } \cline { 6 - 6 } Statistic & $\begin{array}{l}\text { \% of Domestic } \\
\text { company total }\end{array}$ & $\begin{array}{c}\text { \% Decline, } \\
\text { 2008-2009 }\end{array}$ & & $\begin{array}{c}\text { \% of Domestic } \\
\text { company total }\end{array}$ & $\begin{array}{c}\text { \% Decline, } \\
2008-2009\end{array}$ \\
\hline Advertising expenses & 96.5 & -10.8 & & 44.7 & -19.6 \\
R\&D expenses & 46.6 & -16.2 & & 92.3 & -11.9 \\
Capital expenditures & 27.5 & -18.2 & & 25.9 & -21.7 \\
Employees & 50.2 & -2.2 & & 24.4 & -4.4 \\
Sales & 38.6 & -3.5 & & 34.2 & -15.3 \\
\hline
\end{tabular}

Table 1: Statistics for Top 500 Advertisers and R\&D Spenders, 2008 Source: COMPUSTAT North America Fundamentals Annual database 